\title{
Iniciativa BTSF - usposabljanje za izvajanje programov preiskav škodljivih organizmov rastlin
}

\section{Andreja KAVČIČ ${ }^{* 1}$, Barbara SLABANJA ${ }^{2}$}

$\mathrm{Na}$ Oddelku za varstvo gozdov (VARGO) Gozdarskega inštituta Slovenije (GIS) velik del aktivnosti poteka na področju zdravstvenega varstva rastlin. Predvsem je to izvajanje programov preiskav za škodljive organizme (ŠO) rastlin, ki jih v skladu z veljavno evropsko zakonodajo predpisuje in financira Evropska komisija (EK). Namen programov preiskav je hitro zaznavanje in hitro odzivanje na organizme, ki potencialno lahko zelo negativno vplivajo za zdravje rastlin na območju Evropske Unije (EU), z namenom preprečiti škodo, ki bi jo te vrste lahko povzročile. V Sloveniji izvajanje programov preiskav na nacionalni ravni koordinira Uprava za varno hrano, veterinarstvo in varstvo rastlin (UVHVVR). Sodelavci VARGO GIS na podlagi javnega pooblastila UVHVVR izvajamo in koordiniramo na nacionalni ravni programe preiskav ŠO rastlin v gozdovih (žuželke, fitopatogene glive).

Del izvedbe nacionalnih programov preiskav ŠO rastlin v gozdovih pokriva tudi Zavod za gozdove Slovenije (ZGS), in sicer imajo pooblastilo predvsem zaposleni na oddelku za gojenje in varstvo gozdov in na odsekih za gojenje in varstvo gozdov.

$\mathrm{Z}$ namenom zagotavljanja usklajenega izvajanja aktivnosti na področju zdravja rastlin na celotnem območju EU je EK (DG SANTE, Directorate Generale Health and Food Safety) dala pobudo za izvajanje usposabljanj na nivoju EU na področjih zakonodaje, ki zadevajo hrano, krmo, zdravje in dobrobit živali ter zdravje rastlin, tako imenovano iniciativo BTSF (Better Training for Safer Food). Pobuda ima pravno podlago v 51. členu Uredbe (ES) št. 882/2004 Evropskega parlamenta in Sveta o izvajanju uradnega nadzora, da se zagotovi preverjanje skladnosti $\mathrm{z}$ zakonodajo o krmi in živilih ter $\mathrm{s}$ pravili o zdravstvenem varstvu živali in zaščiti živali in 2. členu Direktive Sveta 2000/29/ES o varstvenih ukrepih proti vnosu organizmov, škodljivih za rastline ali rastlinske proizvode, $v$ Skupnost in proti njihovemu širjenju v Skupnosti. Prioritete iniciative BTSF so organizacija in razvoj strategije usposabljanj na nivoju EU s ciljem zagotavljanja in ohranjanja visokega nivoja zaščite potrošnikov, zdravja in dobrobiti živali ter zdravja rastlin, izboljšanja in uskladitve sistemov nadzora škodljivih organizmov rastlin znotraj EU ter med EU in tretjimi državami, zagotavljanja uvoza varne hrane ter zagotavljanja pravične trgovine med EU in tretjimi državami. Usposabljanja se izvajajo od leta 2006 v različnih državah, tako znotraj EU kot izven EU, namenjena pa so strokovnemu osebju, ki deluje na področju zdravja rastlin, iz cele Evrope. Usposabljanja pokrivajo različne tematike s področja zdravja rastlin, kot so izvajanje programov preiskav škodljivih organizmov rastlin, ocene tveganja škodljivih organizmov rastlin in druge.

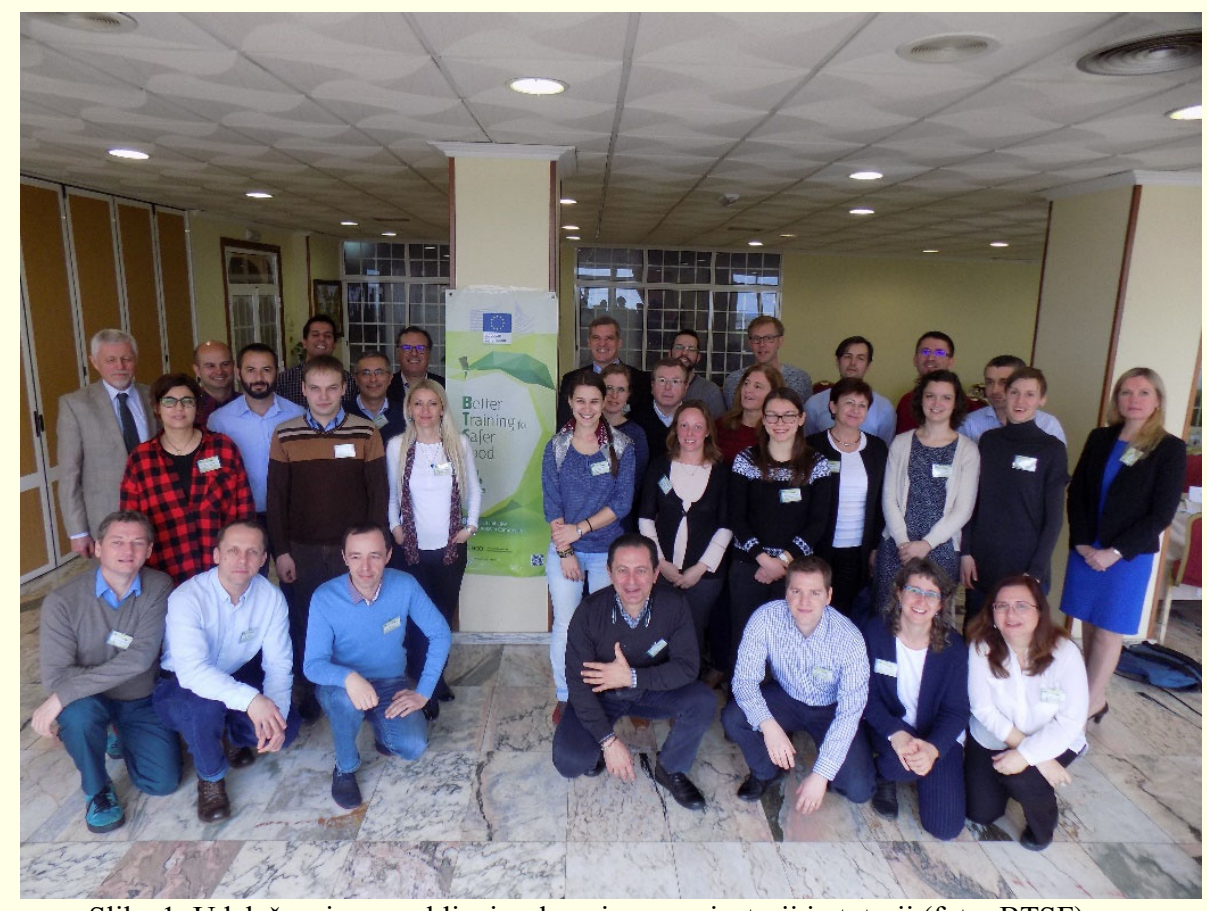

Slika 1: Udeleženci usposabljanja, skupaj z organizatorji in tutorji (foto: BTSF) 
Gre za večdnevne dogodke, ki so sestavljeni iz teoretičnega in praktičnega dela. Teoretični del sestavljajo poglobljene, a jasne predstavitve vseh segmentov izbrane tematike s strani tutorjev, ki prihajajo iz različnih inštitucij. Praktični del usposabljanj je namenjen skupinskemu delu, kjer udeleženci iz različnih držav skupaj rešujejo določen problem, rešitev oz. zaključke pa na koncu predstavijo ostalim udeležencem. Skupinski del je ključnega pomena, saj omogoča izmenjavo mnenj, izkušenj in dobrih praks iz zelo velikega števila evropskih držav z različnimi organizacijskimi strukturami in pristopi, kar je podlaga za plodno iskanje rešitev, ki so sprejemljive za vse. Pomemben del usposabljanja je terenski del, kjer se udeleženci praktično spoznajo z izvajanjem ukrepov za preprečevanje vnosa in širjenja izbrane vrste ŠO. Na vsakem izobraževanju je ciljno obravnavan en ŠO (npr. borova ogorčica, Bursaphelenchus xylophilus). Terenski del udeležencem iz različnih okolij in z različnimi ozadji omogoča neposreden vpogled $\mathrm{v}$ dejansko stanje na terenu, udeleženci iz prve roke spoznajo specifike programa preiskave za izbrani organizem in v živo vidijo, kako poteka izvajanje konkretnih aktivnosti, reševanje konkretnih problemov ter kakšne rešitve so možne $\mathrm{v}$ danih lokalnih razmerah.

$\mathrm{Z}$ namenom zagotavljanja najvišje možne ravni kakovosti izvedbe vseh aktivnosti na področju zdravstvenega varstva rastlin, smo se tako sodelavci VARGO GIS kot tudi sodelavci ZGS v preteklih letih udeležili že več tovrstnih usposabljanj, med drugim na temo izvajanja programov preiskav (Plant Health Surveys).

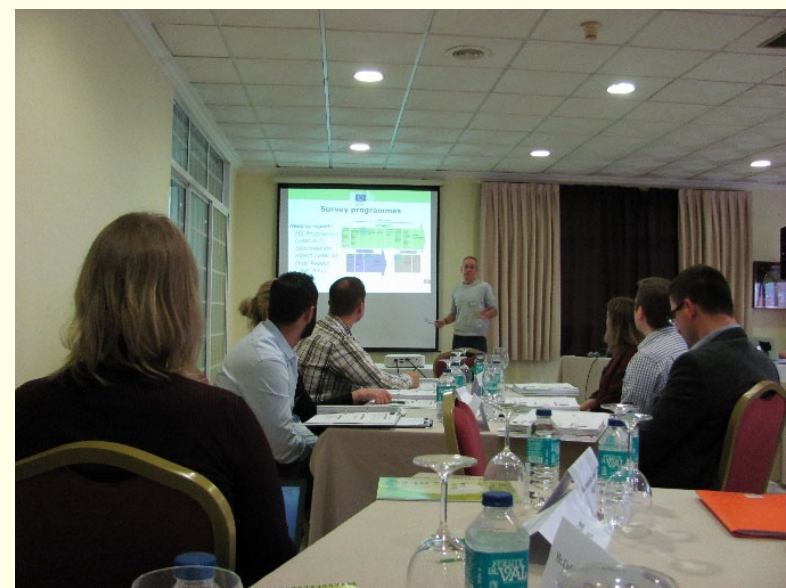

Slika 2: Teoretični del so izvajali tutorji (foto: BTSF)

Eno od usposabljanj na temo izvajanja programov preiskav je potekalo v mestu Vigo v Španiji od 27. 2. do 2. 3. 2017. Usposabljanja se je udeležilo 23 udeležencev iz cele Evrope. Iz Slovenije sva se dogodka udeležili dr. Andreja Kavčič z GIS (VARGO) in Barbara Slabanja iz ZGS, OE Ljubljana. Udeleženci smo pod vodstvom petih tutorjev spoznali vse vidike programov preiskav, od pravnih podlag, mednarodnih standardov in finančnih predpisov, preko načrtovanja in dejanske izvedbe programov preiskav za različne vrste škodljivih organizmov, do poročanja na nacionalni in EU ravni. Pri praktičnem delu smo morali udeleženci med drugim sami v skupinah načrtovati program preiskave za izbrani škodljiv organizem, izdelati načrt njegove izvedbe, na koncu pa na podlagi pridobljenega znanja določiti dobre strani in pomanjkljivosti oz. omejitve pri izvajanju programov preiskav v svojih državah ter na podlagi ugotovitev predlagati možne izboljšave.

Tema terenskega dela usposabljanja je bilo ukrepanje ob izbruhu borove ogorčice, Bursaphelenchus xylophilus. Gre za karantensko vrsto, ki povzroča sušenje borov (Pinus spp.) in za katero so v primeru najdbe na območju EU predpisani strogi ukrepi za preprečevanje vnosa in širjenja. V Sloveniji ukrepe proti borovi ogorčici določa Pravilnik o ukrepih za preprečevanje vnosa in širjenja borove ogorčice (UL RS 45/09). Borova ogorčica je v Evropi zaenkrat prisotna samo na Portugalskem in v Španiji. Prvič se je pojavila na Portugalskem leta 1999, nato pa se je zaradi neučinkovitega ukrepanja razširila v sosednjo Španijo. Na Portugalskem izkoreninjenje borove ogorčice ni več mogoče, v Španiji pa z izvajanjem strogih ukrepov poskušajo preprečevati njeno širjenje.

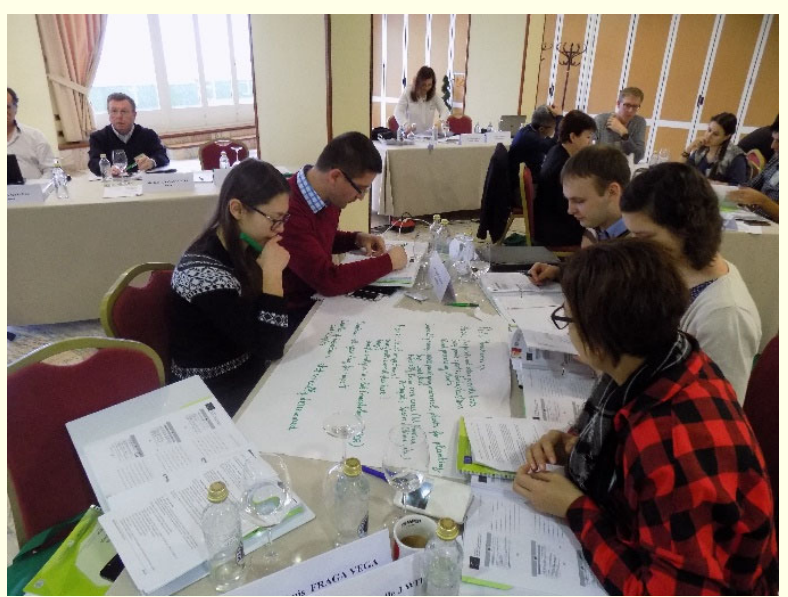

Slika 3: Delo po skupinah (foto: BTSF)

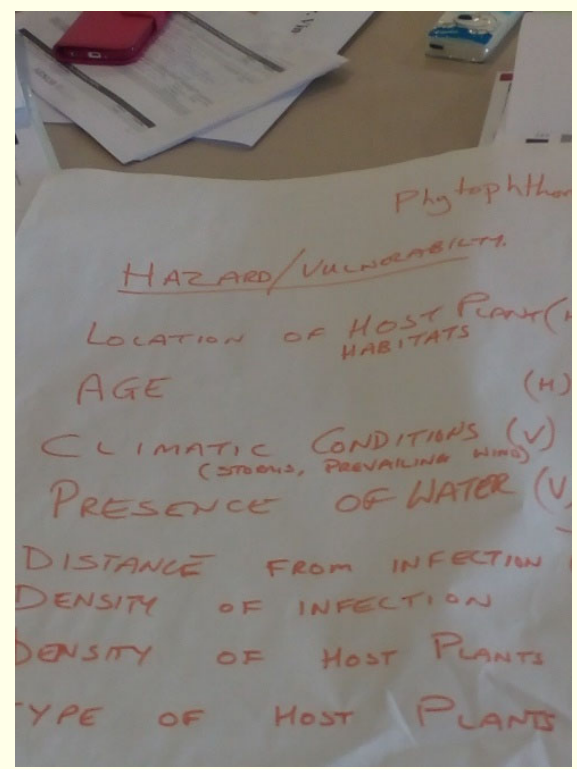

Slika 4: Rezultat skupinskega dela (foto: Barbara Slabanja)

Skupaj s tutorji smo udeleženci obiskali lokacijo saniranega žarišča borove ogorčice v kraju As Neves, kjer sta se izbruha borove ogorčice pojavila leta 2010 in 2016. Izvedeli smo, da je Španija za ukrepe proti borovi ogorčici porabila že več kot 5 mio EUR. Ko je španski nacionalni referenčni laboratorij potrdil okužbo s tem ŠO, je v skladu s predpisi sledil posek vseh gostiteljev v 
pasu $1500 \mathrm{~m}$ (2010) oz. $100 \mathrm{~m}$ (2016) okrog najdbe okuženega drevesa in vzpostavljen je bil intenziven nadzor v pasu 1500-3000 m (2010) oz. 100-3000 m (2016) od okuženega drevesa, ki je vključeval vizualne preglede gostiteljev, vzorčenje simptomatičnih in asimptomatičnih dreves ter vzorčenje s feromonskimi pastmi za kozličke Monochamus sp., ki so potencialni prenašalci borove ogorčice. Ob vsakem od obeh izbruhov so bila izdana posebna navodila za delo v gozdu, na žagah in na skladiščih gozdnih lesnih sortimentov, da bi bila možnost širjenja borove ogorčice na neokužena območja čim manjša. Med drugim je bila na tem območju predpisana prepoved premikov lesa iz okuženega območja v neokuženo območje, izvajale so se cestne kontrole transporta lesa in potekalo je intenzivno informiranje lastnikov gozdov. Zaradi stalne nevarnosti širjenja borove ogorčice iz Portugalske je Španija na meji s Portugalsko vzpostavila $20 \mathrm{~km}$ razmejitveno območje, v katerem stalno potekajo intenziven monitoring in vzorčenje, kontrola transporta lesa in lesnega pakirnega materiala $(\mathrm{LPM}) \mathrm{v}$ cestnem prometu in kontrola na vstopnih točkah v državo. Z namenom preprečevanja vnosa in širjenja tega ŠO poteka monitoring za borovo ogorčico tudi v ostalih delih Španje, vendar je manj intenziven. Pooblaščeni organi izvajajo nadzor na vstopnih točkah v državo, na žagah in na skladiščih ter njihovi okolici. Kontrola je naključna in sistematična, država pa mora o izvajanju ukrepov redno poročati EK (mesečno v primeru izvajanja ukrepov ob izbruhu).

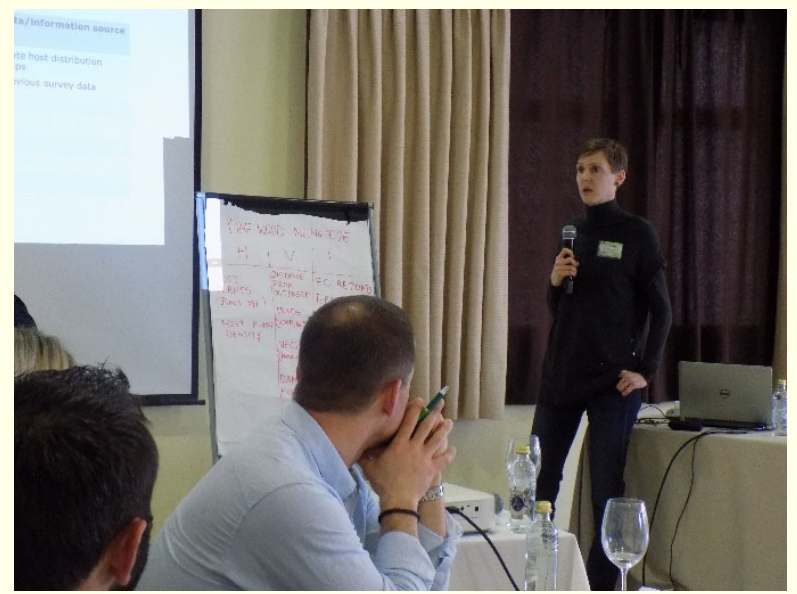

Slika 5: Predstavitev rezultatov skupinskega dela (foto: BTSF)

Glavne težave, s katerimi se pri preprečevanju vnosa in zadrževanju širjenja borove ogorčice soočajo v Španiji, so premalo strokovnega kadra in pomanjkljiva tehnična podpora za izvajanje pregledov in vzorčenj na terenu, nezadostna finančna sredstva, razdrobljeno lastništvo gozdov, ki otežkoča pridobivanje soglasij lastnikov gozdov za izvajanje ukrepov na njihovi posesti, nekontrolirani premiki lesa iz razmejitvenega območja, nezakonit posek dreves in požiganje gozdov, ki spodbujata širjenje potencialnega prenašalca Monochamus $\mathrm{sp}$. in s tem povečujeta možnost širjenja borove ogorčice, ter uničevanje feromonskih pasti zaradi vandalizma. Lokalni predstavniki so poudarili, da je za večji in dolgoročno vzdržen uspeh med drugim treba povečati učinkovitost osveščanja javnosti, racionalizirati upravljanje $\mathrm{z}$ denarjem in vzpostaviti boljše sodelovanje med Portugalsko in Španijo, saj morajo biti ukrepi na obeh straneh meje usklajeni, sicer uspeh ni zagotovljen.



Slika 6: Predstavitev problematike na terenu (foto: Barbara Slabanja)

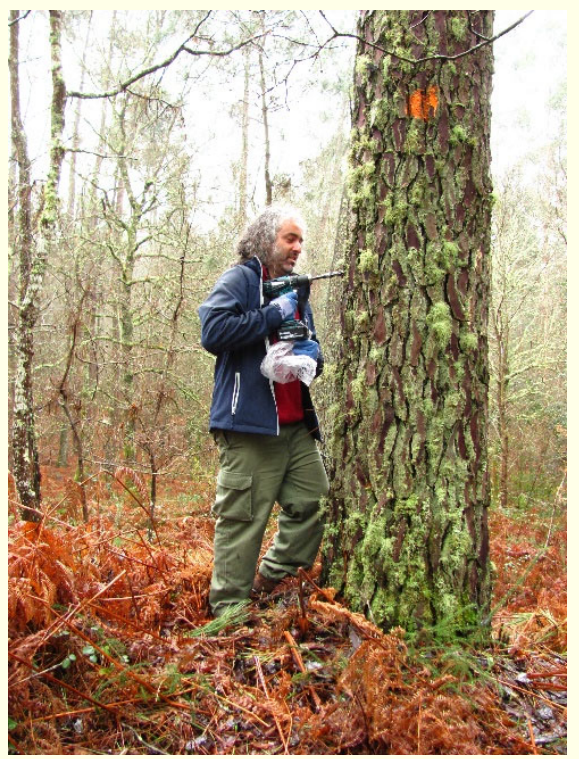

Slika 7: Prikaz odvzema vzorcev za testiranje na prisotnost borove ogorčice, Bursaphelenchus xylophilus (foto: A. Kavčič)

Usposabljanje na temo izvajanja programov preiskav v Španiji je doseglo svoj namen, saj je udeležencem na enem mestu ponudilo vse potrebne informacije na področju izvajanja programov preiskav ŠO rastlin, razjasnilo nekatera že znana dejstva in nas seznanilo z novostmi na tem področju. Ključnega pomena je bilo skupinsko delo in sodelovanje s strokovnjaki z različnih področij zdravstvenega varstva rastlin iz različnih evropskih držav, saj je intenzivna izmenjava različnih mnenj, izkušenj in dobrih praks spodbujala razvoj novih idej in predlogov za izboljšave za usklajeno izvajanje aktivnosti programov preiskav znotraj celotne EU, hkrati pa razjasnila marsikatero dilemo kako, če sploh, ukrepati v določenih primerih. Udeležba na tovrstnih mednarodnih usposabljanjih je za strokovnjake, ki delujejo v mednarodnem okolju nujna, zato se jih bomo sodelavci VARGO GIS še naprej udeleževali.

${ }^{1}$ Gozdarski inštitut Slovenije, Večna pot 2, 1000 Ljubljana; ${ }^{2 Z a v o d ~ z a ~ g o z d o v e ~}$ Slovenije, Tržaška cesta 2, 1000 Ljubljana *andreja.kavcic@gozdis.si 